CIC. Cuadernos de Información y Comunicación ISSN: 1135-7791

http://dx.doi.org/10.5209/CIYC.55979

\title{
Sesenta años del premio de fotoperiodismo Word Press Photo of the Year: una visión con perspectiva de género
}

\author{
Asunción Bernárdez Rodal ${ }^{1}$; Ignacio Moreno Segarra²
}

Enviado: 22 de abril de 2017 / Aceptado: 28 de abril 2017

Resumen. Este artículo se centra en los premios Word Press Photo of the Year desde el año 1955 hasta el año 2015 como repertorio significativo para estudiar cómo el fotoperiodismo construye las diferencias de género respecto al sufrimiento humano. Para conseguir este objetivo, primero hablaremos de la importancia del premio en el contexto de la prensa internacional, definiendo los rasgos del fotoperiodismo en un mundo de imágenes globalizadas. Segundo, haremos una revisión de los trabajos más importantes realizados sobre estos premios, $y$, tercero, analizaremos de forma crítica la presencia de las mujeres en estas imágenes para determinar hasta qué punto el cuerpo de las mujeres sirve para representar la globalidad o la particularidad de los desastres y los traumas humanos.

Palabras clave: Fotoperiodismo; Word Press Photo; Estudios de Género; Espectacularidad; Estudios Visuales

\section{[en] Sixty Years of Word Press Photo of the Year' Photo-journalism: a view from a gender perspective}

\begin{abstract}
This paper will focus on the Word Press Photo of the Year awards from 1955 to 2015 as a major repertoire to study how photojournalism builds gender differences in relation to human suffering. To achieve this objective, first, we will talk about the importance of the prize in the context of the international press, defining the features of photojournalism in a world of globalized images. Second, we will review the most important work on these awards and, third, we will critically analyze the presence of women in these images to determine the extent to which the body of women serves to represent the globality or particularity of disasters and traumas humans.
\end{abstract}

Keywords: Photojournalism; Word Press Photo; Gender Studies; Spectacular; Visual Studies.

Sumario. 1. Introducción. 2. Word Press Photo como objeto de estudio y presupuestos metodológicos. 3. El fotoperiodismo, la banalidad de las imágenes y la exigencia de verdad. 4. La representación pública de las mujeres. 5. El análisis del repertorio. 5.1. Cuestiones generales sobre el corpus del análisis 5.2. "Nuestro sufrimiento" vs "el sufrimiento de "los/as otros/as". 5.3. Resultados del análisis con perspectiva de género. Conclusiones. Bibliografía citada.

Cómo citar: Bernárdez Rodal, A.; Moreno Segarra, I. (2017). Setenta años del premio de fotoperiodismo Word Press Photo of the Year: una visión con perspectiva de género, en CIC. Cuadernos de Información y Comunicación 22, 282-303.

\footnotetext{
1 Universidad Complutense de Madrid.

Email: asbernar@ucm.es

2 Universidad Complutense de Madrid.

Email: Igmore01@ucm.es
} 


\section{Introducción}

Word Press Photo es una organización independiente y sin ánimo de lucro con sede en Amsterdam fundada en 1955. Desde ese año convoca un premio anual de fotoperiodismo que sigue siendo el más prestigioso del mundo, aunque en la actualidad existen otros muy importantes como el Pulitzer o el Sony. Todos los fotógrafos de prensa profesionales pueden presentar sus trabajos a este premio, que compiten cada año ante un jurado independiente de trece miembros que pertenecen al mundo profesional. En la actualidad, además del primer premio se conceden también otros por categorías: noticias y temas de actualidad, personajes, deportes y fotografías de acción, vida cotidiana, retratos, arte y entretenimiento, naturaleza y reportajes de deportes, respondiendo así a un afán de diversificación y especialización que es muy propio de nuestro tiempo. La organización Word Press Photo tiene una de las webs de referencia en cuanto a imágenes públicas se refiere. La relevancia de la organización se debe también a su gran difusión en el mundo entero ya que, tras el concurso, las fotografías premiadas se exhiben en una exposición itinerante en cuarenta países, recibiendo más de un millón de visitantes cada año. Además, se publica un anuario en seis idiomas diferentes, y la organización desarrolla programas educativos por todo el mundo.

En su sitio web (https://www.worldpressphoto.org/) la organización declara que los objetivos de la organización son "estimular el desarrollo del fotoperiodismo, fomentar la difusión del conocimiento, ayudar a consolidad altos cánones profesionales dentro del sector e impulsar un intercambio gratuito y sin restricciones de información." Word Press Photo se muestra así como una organización consciente de la importancia de las imágenes periodísticas en la construcción y la percepción de un mundo globalizado (Beck, 2000), y uno de sus lemas es que esas imágenes que se emplean en los entornos informativos, pueden servir "...to change the world and inspire understanding". Esta declaración resume la idea de la importancia adquirida por la fotografía de prensa a lo largo del siglo XX, a la hora de proporcionar imágenes de todo el mundo, sobre todo en contextos bélicos o de catástrofes humanitarias. Si hacemos un repaso a las fotografías premiadas, veremos cómo los galardones van dibujando un mapa de los principales conflictos que asolaron el mundo después de la Segunda Guerra Mundial (y que más preocuparon al bloque occidental). Por ejemplo, la organización concedió el galardón a fotografías tomadas en la Guerra del Vietnam (1955-1975) en cinco ocasiones: 1965, 1966, 1967, 1968 y 1973. Este conflicto ha sido uno de las más fotografiados en la historia, y es el ejemplo más evidente de cómo el fotoperiodismo ha sido capaz de movilizar políticamente a la ciudadanía en el mundo occidental. El conflicto palestino-israelí, la Guerra de Yugoslavia, el conflicto del Líbano, las masacres de Ruanda, las Guerras de Irak, los golpes de estado en distintos o países, o en estos momentos la guerra en Siria y la dramática entrada de refugiados en Europa nos llegan a través de las imágenes proporcionadas por unos profesionales dedicados no sólo a informar, sino a recrear la barbarie de las guerras y las calamidades humanas, al mismo tiempo que proporcionan argumentos en forma de imágenes al Occidente crítico que quiere cambiar el estado de violencia en la que siguen viviendo muchas partes del mundo globalizado, deslegitimando las intervenciones armadas y la violencia indiscriminada. 


\section{Word Press Photo como objeto de estudio y presupuestos metodológicos}

Los premios de fotografía han sido el objeto de estudio de varios artículos académicos en los últimos diez años ${ }^{3}$. Por ejemplo, las imágenes ganadoras del Premio Pulitzer entre 1942 y 2002 han sido estudiadas por Kim y Smith (2005), Buel, (1999) y Greenwood, K. \& Smith, C. Z. (2007) quienes analizaron las representaciones dominantes en ellas. También el premio principal del World Press Photo que nos ocupa ha sido el objeto de análisis en varias ocasiones. Por ejemplo Karzycka y Kleppe (2013), han investigado qué significado tienen los "tropos" que aparecen en las fotografías premiadas durante varios años, analizando la repetición de una serie de elementos significativos a través del tiempo. Una de las conclusiones de este trabajo fue la idea de que una de las claves fundamentales del uso de los tropos en este tipo de imágenes es la construcción dicotómica de los géneros: masculino y femenino siguen concretándose en una serie valores opuestos de la forma más convencional en nuestra cultura. Este trabajo, sin embargo, no recorre la historia del premio, sino que se limita a los años 2009 al 2011.

Por su parte, un artículo de Yang Lui (2013) analiza los discursos profesionales implícitos en las imágenes ganadoras entre el año 1992 y 2011, en la modalidad de medioambiente, estudiando la relación entre las claves profesionales de representación en relación con la verdad y la presencia de las ONGs en países en desarrollo. El texto de Natalia Mielczarek (2013) ofrece un análisis de la retórica visual del premio del año 2011 concedido al español Samuel Aranda en la que una mujer tiene en su regazo a un hombre herido, y cómo esta imagen tomada en Yemen, representa en realidad a la madre tradicional de la cultura musulmana. Por último Joanna Kedra (2013) ha elaborado un modelo de análisis de imágenes que sea utilizable en el contexto educativo para desarrollar proyectos de alfabetización audiovisual. Es un artículo metodológico que utiliza como casos de estudio el fondo de imágenes Word Press Photo en la variedad press photograph story, en el que se utilizan una secuencia de entre ocho y doce imágenes.

Word Press Photo, ha sido uno de los hitos del fotoperiodismo después de la Segunda Guerra Mundial, una actividad profesional que en su producción de imágenes ha ido creando un contexto visual específico y significativo. Una cultura visual construida a base de poner ante los objetivos de las cámaras los conflictos y las desgracias humanas. Junto con ello es innegable que el sufrimiento retratado no sólo denuncia periodísticamente sino que ayuda a que la información se venda e ilustra de manera obscena nuestros telediarios. Nuestra primera hipótesis en este sentido es que este tipo de imágenes muestran el sufrimiento humano, pero también ponen los límites a su exhibición y comprensión seleccionando aspectos de la realidad, es decir, no muestran "el mundo", sino una parte reconocible de él. Partiendo de esa premisa vamos a analizar cuáles son las formas preferidas por las y los fotógrafos de mostrar el sufrimiento; sabiendo que estas imágenes son también las que los miembros de los jurados han elegido por considerarlas mejores, en el sentido de más eficaces.

Nuestra segunda hipótesis es que, dentro de este contexto visual, las mujeres han servido para representar el trágico desgarro físico y emocional de los seres humanos sometidos a la brutalidad de otros (Butler, J. 2006 y 2009, Rogers, Kenix y Thorson,

Los análisis sobre premios fotográficos pueden rastrearse más allá de los diez últimos años. Vid. Por ejemplo, Greenwood, K. Y Smith C. Z. (2009) 
2007). En ese contexto los cuerpos femeninos reciben un tratamiento estético particular que las convierte en víctimas, no sólo como mujeres, sino como símbolos de la representación posmoderna de la tragedia humana.

Si bien las imágenes de prensa se interpretan dentro de un marco significativo que nos habla de un suceso "que es verdad", el horror y el sufrimiento que representan necesita de una interpretación (Wright, 2000). El contexto general en que los medios ofrecen estas imágenes no favorece los análisis racionales ni de contenido político. Por ejemplo, una fotografía de un niño refugiado muerto en una playa europea, no es sólo la representación de una realidad, sino el drama humano -eterno y no históricodel fallecimiento de un niño en terribles condiciones. Esa trascendencia que tiene la imagen es en sí misma es paradójica porque, al mismo tiempo que muestra una realidad, por si capacidad simbólica parece desestimar aproximaciones más racionales, de tipo económico o político. Interpretar el horror, verbalizarlo, buscar sus causas y sus consecuencias parece un ejercicio imposible. El fotoperiodismo cumple así una doble función: por un lado nos trae ante nuestros ojos los dramas más terribles que puede vivir el ser humano, pero por otro, hace que los esas tragedias aparezcan de una forma impactante, pero no explicativa (Chouliaraki, L. 2010). Como veremos cuando analicemos la serie de fotografías premiadas, el sufrimiento humano, la tragedia y la conmoción responden y se plasman de forma indistinta, sea que provengan de una catástrofe natural, de una guerra o una mala gestión política.

En nuestro análisis, hemos partido del trabajo realizado por Karzycka y Kleppe (2013), de la definición de aportan sobre qué es un tropo, pero ampliamos nuestro corpus de análisis a un período más amplio que va del año 1956 al año 2015. El sentido que tiene ampliar el corpus es comprobar en qué medida, las claves de representación del género están cambiando en la medida en que las mujeres han ido transformando sus roles sociales y representativos en los últimos cincuenta años. Nuestra hipótesis fuerte es que la representaciones de la cultura mainstream suelen tener un fondo especialmente conservador respecto al género, rasgo que comparte con las representaciones de la "alta cutura". Las imágenes producidas por el fotoperiodismo y premiadas por el Word Press Photo, son ejemplos de imágenes que están presentes tanto en la cultura popular como en la artística, en un hibridismo típico de la posmodernidad.

El análisis lo realizaremos a tres niveles, siguiendo el paradigma de la semiótica clásica de Roland Barthes (1977: 17), así como las pautas de observación "extrañadas" de la habla Rose (2012): nada de lo que vemos en una fotografía es evidente, sino fruto de una elaboración y una interpretación creativa. La imagen es un mensaje sin código, pero sus elementos son interpretables por analogía. Es decir, las imágenes tienen un valor denotativo de referencia, pero también un valor connotativo asociado a un código social necesario para interpretar lo que vemos. Las interpretaciones de las imágenes de este tipo son altamente contextuales. Los factores culturales, el contexto en el que se leen las imágenes o la competencia cultural de los y las receptoras son cruciales a la hora de generar una determinada interpretación. Tendremos en cuenta los valores denotativos, los connotativos, y también las interpretaciones "sociales" (Hall, S. 1997) que tengan consecuencias en la construcción de los géneros como dos entidades opuestas, que es la estrategia básica de la representación de género en los medios de comunicación. Esta complejidad analítica nos lleva a desarrollar en la práctica un método hermenéutico de interpretación (Bock, A; Isermann, H. Y Kniper, T. 2011), porque es necesario aplicar una serie de conocimientos 
interdisciplinarios que nos expliquen el complejo mecanismo de la construcción de los géneros. Analizar imágenes de prensa, requiere como decía Clifford Geertz llevar a cabo una "descripción densa" (1997: 20), que no se agota en la mera descripción de los signos que contiene y las relaciones que mantienen entre ellos. En este caso, ese tipo de relaciones deberán ser sometidas a la referencia cultural de cómo se construye la diferencia de los géneros de una forma completamente estereotipada y dicotómica: lo femenino se expresa por los cuidados, el sacrificio por los demás y la empatía, y lo masculino por la actividad, el combate y la lucha.

\section{El fotoperiodismo, la banalidad de las imágenes y la exigencia de verdad.}

En el mundo globalizado, la fotografía de prensa sigue teniendo un papel importante en el panorama de la comunicación (Cottle, S. 2009; Lewis, S. C, Kaufhold, K., y Lasorsa, D. L. 2010). En una ecología mediática en la que tanto la obtención como la difusión de imágenes se ha banalizado, las fotografías que aparecen en la prensa siguen manteniendo su estatus como portadoras de valores simbólico y material. Este hecho lo debemos achacar a que el elemento diferenciador de las imágenes producidas por el fotoperiodismo con respecto a otro tipo de fotografías es la pretensión de que sus imágenes son "verdaderas" y hablan del mundo del forma "objetiva". Los fotógrafos asumen que su función es hablar de la verdad, aunque su papel está más cercano a la mediación social, ya que, al fotografiar la realidad de una forma concreta, la interpretan. Sin embargo, el objetivo profesional de los fotoperiodistas consiste en hacer invisible ese proceso de mediación (Schwartz, 1999). Entre las exigencias profesionales del fotoperiodista está la de estar presente en el lugar donde los hechos ocurren, observarlos directamente, y no manipular los elementos visuales (color, luz, etcétera) de forma exagerada hasta distorsionar la realidad. Cuando alguien no cumple con estos requisitos puede ser "sancionado" socialmente dentro de la profesión. Un ejemplo de este proceso de exigencia de verdad se dio cuando la organización de los premios retiró el año 2010 el tercer premio de la categoría de Noticias Deportivas concedido al fotógrafo Stepan Rudik por haber manipulado una imagen. Sabemos que en la actualidad las líneas entre la "literalidad" de las imágenes tanto en la obtención de la misma como en su interpretación es un proceso complejo, especialmente en un mundo donde la fotografía digital y su tratamiento técnico ha revolucionado nuestra relación con las imágenes. En este panorama cambiante, el fotoperiodismo se ha convertido en el garante de la relación especialmente estrecha que se supone que guarda la fotografia y la realidad (Newton, J. H. 2008). El periodista debe asegurarse no sólo de que capta la realidad en un ángulo determinado, sino de que los receptores interpretan de la forma más literal posible lo que ven. Para eso, cuanto más cerca esté del objeto a captar, mejor será entendido el sentido por quienes miran la imagen. Es decir, la denotación de la imagen debe estar muy "cercana" a los valores connotativos e interpretativos que se aportan en el proceso de recepción. La cuestión de hasta qué punto pueden llevarse a cabo los retoques en las imágenes sobre todo desde que se ha impuesto la fotografía digital, es un tema muy interesante porque marca las líneas profesionales del fotoperiodismo, pero no es un tema que podamos tratar en este artículo (Vid. Mäenpää, 2014). Las fotografías que podemos enmarcar en el epígrafe del "fotoperiodismo" no suelen dejar lugar a la ambigüedad interpre- 
tativa. Word Press Photo, en su declaración de intenciones, indica cuál debe ser el sentido del hacer periodístico en un mundo globalizado y altamente tecnológico:

Accuracy, impartiality, fairness, transparency, and accountability are the core values we promote, and World Press Photo's integrity is maintained when we put them into practice. New technologies have expanded the ways and means of doing journalism, meaning it is no longer synonymous with the printing press. The rise of digital technologies and the Internet has transformed the way we produce, publish, circulate and consume visual stories. Amidst this upheaval, our advocacy of free inquiry, free expression, free speech, and a free press is stronger than ever.

Para la organización, el periodismo es una forma de producir historias sobre el mundo. Y las tecnologías digitales y su enorme difusión a través de Internet, han transformado la forma de contar esas historias, pero también de producirlas. En ese mundo globalizado (Cottle, 2009), sin embargo, permanece una constante cultural que los medios de masas no han inventado, pero sí difundido y explotado al máximo: la fascinación por la violencia y el sufrimiento (Höoijer, 2004) como un elemento de popularidad tanto en la información como la ficción. Inmersa en ese esquema podríamos afirmar que la actividad fotoperiodista desarrolla una crítica implícita (Moeller, S. D. 1999) a los sucesos sociales que representa, y en concreto a la violencia. Hannah Arendt decía ya en un texto de 1963 (On Revolution) que en la modernidad se había desarrollado una "política de la piedad" frente al sufrimiento ajeno que no existía en períodos históricos anteriores. La visión del sufrimiento a través de imágenes, ha sido un recurso para fomentar la empatía con los otros. El fotoperiodismo del siglo XX ha contribuido de forma especial al desarrollo de un nuevo paradigma de la visualidad, porque como explica Didier Fassin (2015), con esas representaciones se ha pasado a la representación de una nueva "política del sufrimiento". Los individuos fotografiados pasan a ser seres sufrientes a través de los cuales podemos observar la "patetización del mundo" como fenómeno globalizado (Boltanski, 1999; Ilan, 2015). Hombres y mujeres que sufren se convierten en los objetos omnipresentes en los medios de comunicación. Sin embargo podemos preguntarnos si ambos géneros (masculino y femenino) cumplen las mismas funciones representativas, tienen el mismo valor, o si apelan a los mismos sentimientos de los espectadores. ¿Tiene el mismo sentido la exhibición de los cuerpos de hombres y mujeres sufrientes en las fotografías periodísticas que vemos? Nuestra hipótesis principal es que ambos arrastran consigo los valores connotados de los géneros sexuales en el resto de representaciones mediáticas. De una forma bastante convencional, se mantiene una estructura dicotómica en la que los hombres son activos, capaces de usar la fuerza, intervienen en el entorno, y las mujeres son sobre todo seres sufrientes, cuyo dolor es sobre todo el dolor de los demás. La función de los hombres es la de la protección de los débiles, mientras que las mujeres son las débiles frente a un sistema o circunstancia que las sobrepasa.

\section{La representación pública de las mujeres}

Si tuviéramos que señalar un rasgo definitorio de la sensibilidad posmoderna que aúne distintas manifestaciones artísticas o creativas, indicaríamos que los conceptos 
de "subjetividad" o "identidad", han marcado todo un período crítico y creativo. Para la teoría feminista, también esos conceptos han sido los ejes centrales en torno a los cuales se han desplegado los discursos sobre cómo se entienden las categorías del pensamiento feminista clásico. La sensibilidad posmoderna ha impuesto un rasgo constructivo en todos los procesos identitarios, y ya no está tan interesadas en explicar tanto los procesos sociales, como las construcciones subjetivas. Así, la crítica teórica posmoderna ha renunciado a explicar por ejemplo qué es el patriarcado, o por qué se restituyen en la mayoría de las manifestaciones culturales la insidiosa categoría dicotómica que construye lo femenino y lo masculino como dos entidades enfrentadas y contrapuestas, pero que dan sentido una a la otra. Sin embargo, esos argumentos posmodernos se ven seriamente cuestionadas cuando dejamos la teoría y nos centramos en analizar prácticas sociales y las representaciones culturales. La realidad es que las mujeres siguen siendo representadas de forma estereotipada o infra-representada en los medios, que los datos económicos y de igualdad arrojan año tras año unas cifras de grandes desigualdades de las mujeres en el mundo. La desigualdad económica y social siguen existiendo, pero también sigue existiendo la desigualdad de tipo simbólico de la que hablaba Nancy Fraser (1997), exponiendo que la consecución de la igualdad para todos los seres humanos pasa per recorrer dos caminos: el que tiene que ver con la justicia económica, pero también el que tiene que ver con la justicia representativa.

¿Qué está ocurriendo en este caso con la imagen de las mujeres en las nuevas formas de producir, acumular y distribuir imágenes en el mundo globalizado? ¿Siguen respondiendo las representaciones femeninas a las expectativas tradicionales respecto a la forma de construir los género? Las imágenes están en todas partes, en los anuncios publicitarios, en el cine, en los materiales formativos, en las distintas formas de ocio. Son ubicuas, banales, sin perder, sin embargo de forma paradójica, su capacidad de hablar, de recrear y dar sentido al mundo (Machin, D. 2004). Pero tomemos un ejemplo de cómo las nuevas formas de producir, reproducir y consumir imágenes puede estar cambiando los valores simbólicos de la feminidad. Veamos qué está haciendo, por ejemplo, una de las grandes distribuidoras de imágenes, la base de datos Getty Images, capaz de diseminar millares de fotografías, llegando a cualquier nicho de mercado proporcionando material a cualquier subgénero que produzcan los medios de comunicación. Esta base proporciona "nuevas imágenes" que deconstruyen la forma de representar los géneros en la imaginería convencional, utilizando un lenguaje posmoderno que procede en algunos casos de los postulados de la teoría queer. En un artículo Aiello y Wodhouse (2016) analizan en particular el descriptor de búsqueda /Genderblend $/ 4$, como "Visual Trends 2015 " en la base de imágenes de la Fundación Getty. El término alude a la tendencia estética actual de borrar las fronteras tradicionales respecto a los roles de género. Podemos preguntarnos por ejemplo: ¿ya no es tendencia que las mujeres aparezcan asociadas a la belleza, a la debilidad, a la emocionalidad como ha ocurrido hasta ahora? La respuesta intuitiva es que esto no ha ocurrido. Lo que es evidente es que en la cultura comercial, las marcas han aprendido a jugar con las claves de la representación dicotómica de los géneros, y sin abandonarla, son capaces de tratar temas como el empoderamiento de las mujeres o la importancia de la crianza de los bebés por parte de los hombres.

Es evidente que en las grandes bases de datos son importantísimos los términos claves para realizar las búsquedas. De ahí la importancia de la creación de la etiqueta /genderblend/. 
Es evidente que están de moda, por ejemplo, publicitar juguetes para niños y niñas, o jugar con las representaciones transgénero. En el año 2015 Getty Images dedicó un seminario web que tituló: Genderblend: The new visual language of gender marketing. Esta entrada de los nuevos discursos sobre el género en la publicidad y el márquetin podría hacernos pensar que estamos viviendo un momento en que ya no existen las fronteras respecto al género. Sin embargo, cuando abandonamos este terreno de la publicidad, y entramos en representaciones con mayor consideración por su aspecto informativo, como son las del fotoperiodismo y las imágenes que se transmiten en los medios legitimados de información, el genderblend desaparece. Las mujeres siguen siendo objetualizadas y representadas en sus rasgos clásicos de definición de género: emocionales, empáticas, débiles y hermosas.

En la serie de imágenes que vamos a analizar, que tienen a las mujeres como sujetos principales de las fotografías premiadas, veremos como ellas están ahí para representar valores convencionales: mujeres sufrientes que lloran el mal de los otros, de los seres queridos, haciendo suyo su dolor y por extensión el dolor humano.

Estas imágenes de mujeres sufrientes son un lugar privilegiado desde donde ver como esa subversión y mezcla de géneros que nos ofrece el medio publicitario y la ficción, materializada en formas de consumo mediático, contrasta y enmascara no sólo las imágenes tradicionales de género sino la realidad social y material que las soportan. Dicho de otro modo: las imágenes periodísticas nos recuerdan que hace falta algo más que el desmontaje de los géneros en el ámbito consumo para que desaparezcan de nuestra realidad social.

\section{El análisis del repertorio}

\subsection{Cuestiones generales sobre el corpus del análisis}

El corpus de análisis han sido las 58 fotografías premiadas entre los años 1955 y 2015 , teniendo en cuenta que durante cuatro años el concurso no se llevó a cabo $(1958,1960,1970$ y 1971). Nuestra investigación tiene como objetivo principal fijarnos en el papel de las mujeres como protagonistas de las fotografías ganadoras. Para ello hemos realizado una comparativa con las imágenes en las que se narran historias masculinas. Los temas que se tratan en ellas recorren la historia política y social desde la segunda mitad del siglo XX hasta nuestros días. La serie comienza en 1955 con la imagen de un accidente de motocicleta, y termina en 2015 con la fotografía de un grupo refugiados que llegan a Europa desesperados desde Siria. Cada año el Premio ha ido señalando los conflictos sociales más candentes, como las consecuencias de la II Guerra Mundial, la segregación racial, el asesinato político, la conmoción de la Guerra de Vietnam, los golpes de estado en países como Chile y España, el conflicto de Irlanda del Norte, las catástrofes naturales, el Apartheid en Sudáfrica, el hambre en el mundo, el conflicto palestino-israelí, el problema del Sida, los desalojos de los hogares por la crisis económica, la discriminación de los gays, los "sin papeles" intentando cruzar el Mediterráneo, etcétera ${ }^{5}$.

En este caso, tomamos un repertorio construido con un alto grado de artificialidad. Se trata de fotografías elegidas anualmente por distintos jurados, y que, por

Puede consultarse toda la serie en la Web oficial https://www.worldpressphoto.org/ 
ello, cubren una gran variedad de temas y técnicas. En nuestra investigación somos conscientes de que con la elección de la foto premiada de cada año construimos un "repertorio de obras" que no ha sido construida para ser vista de esta manera. Puede ocurrir que, al mismo tiempo, al extraerlas de su entorno y mirarlas sucesivamente, nos otorguen una serie de significados que ninguna tenga de manera individual. Estas fotografías que en un principio parecen no tener nada en común, sólo el hecho de haber sido producidas y premiadas en el entorno periodístico pueden legítimamente someterse a una lectura conjunta, utilizando el concepto que Foucault (1999:62) definió como "formación discursiva". La formación discursiva es en realidad un discurso que cobra sentido por sus propios medios, a pesar de no realizar el análisis sobre un objeto convencional de estudio cerrado en sí mismo, como puede ser, por ejemplo, un libro. Este sistema nos sirve para saber cuáles han sido las condiciones históricas y este caso profesionales, es decir, el a priori histórico que ha hecho que en un momento determinado se hayan producido ciertos textos y no otros. En este caso, la pregunta es por qué se premian unas obras y no otras, y cuál es la presencia de las mujeres en ellas, tanto como objetos de representación y como creadoras de las imágenes. Las obras premiadas se convierten así en un discurso con sentido, en un repertorio interpretable a través de las reglas generales para interpretar textos visuales. Por ejemplo, podemos plantearnos frente a este grupo de fotografías las siguientes preguntas: ¿Qué reglas profesionales (y anónimas) dominan en este lenguaje audiovisual?, ¿quiénes hablan y a quién se habla con estas imágenes? ¿qué temas dominan?, ¿qué sujetos aparecen y cómo se relacionan con los objetos?, ¿qué estrategias de la imagen predominan en las composiciones? En algunos casos, nos conformaremos con señalar los elementos que se repiten de manera estable: el predominio formal del blanco y negro sobre las fotografías en color, la elección de temas que hayan tenido repercusión mediática, la preferencia por mostrar el sufrimiento de los grupos humos frente a los individuos, etcétera.

En estas fotografías, hay varios elementos que se repiten en todas ellas, constituyendo una red significativa, unida por interpretaciones comunes sobre los roles de las mujeres y los hombres en la vida social. Un punto común, por ejemplo, es que todas las fotografias presentan a seres humanos que están sufriendo. Podemos ver personas individuales o en grupo, de distintas edades, hombres y mujeres, pero todos ellos expuestos a desgracias como la muerte, la enfermedad, la guerra, los accidentes, las pérdida del hogar, de la familia, el hambre, la marginación o los desplazamientos forzosos. Los vemos como cuerpos que sufren y no sólo como fotografías estáticas que reflejan un momento ya pasado. Las leemos en su contexto histórico, como una narración de lo que les ha ocurrido a unos seres humanos llevados al límite de precariedad y debilidad. Cada imagen es una historia, son, por ello, fotografías narrativas. Por ejemplo, cuando vemos una imagen de personas afectadas por una guerra o un desplazamiento, podemos también reflexionar sobre cómo se ha producido esa guerra, qué papel están teniendo los países occidentales en el conflicto, etcétera. No podemos saber qué les ha pasado a esas personas de forma individual, cuales han sido sus historias o dónde están ahora mismo. Y sin embargo, las fotografian apelan directamente a nuestra capacidad de emocionarnos y desarrollar un sentimiento de solidaridad hacia lo que vemos.

La definición es "un conjunto de reglas anónimas, históricas, siempre determinadas en el tiempo y en el espacio, que han definido en una época dada, y para un área social, económica, geográfica o lingüística dada, las condiciones de ejercicio de la función enunciativa" (AS, 153-154). 
De esta serie fotográfica podemos extraer una serie de tropos que se repiten. Podemos definir un "tropo" como una "imagen fuerte" (Zarzycka y Kleppe, 2013: 972) que intenta conmovernos, aludiendo a una serie de convenciones iconográficas reconocidas por todos nosotros. Una mujer de luto, una mujer que llora de forma desgarrada, un civil frente los militares, una persona ensangrentada... son imágenes que tienen una identidad en sí misma, capaz de trascender el tiempo y el espacio en el que fueron tomadas. Los tropos van más allá también los valores puramente estéticos y pueden ser interpretados desde su valor político. Parece que nos están diciendo que algo va mal en este mundo, y que algo deberíamos hacer por cambiarlo. En este sentido, Didi-Huberman (2008) en su análisis sobre las fotografías de los campos de concentración nazi, habló no sólo de la hipertrofia que pueden llegar a producir este tipo de imágenes fuertes, sino también de que pueden llegar a representar lo que consideramos irrepresentable, saliéndose de lo que consideramos como razonable, y por lo tanto humano. El mismo autor plantea también un argumento interesante: en la semiótica tradicional, los tropos eran analizables a partir de los distintos niveles de significado que cada signo contenía, de tal forma que existía un lazo explícito entre lo que una imagen representaba y lo que los lectores o espectadores podían reconocer como elementos significativos. Hoy en día, sin embargo, los niveles de reconocimiento de las imágenes son más complejos. En primer lugar, el público sabe que las imágenes pueden ser producidas por una gran variedad de agentes como distintas instituciones, medios de comunicación, o personas individuales que producen fotografías que son recibidas a través de Internet de una forma totalmente desvinculada de la situación en que se tomó. Las imágenes hoy en día funcionan más como modelos abstractos que como documentos (Rosler, 2004) de unos hechos que de verdad han ocurrido. Son una moneda de cambio que circula por las nuevas redes porque pueden ser vendidas en el mercado. Por ejemplo, una mujer de luto sigue siendo un símbolo religioso del dolor por la muerte de un ser querido, pero también es una categoría que puedes ser buscada en una base de datos y ser utilizada en distintos soportes como simple ilustración.

El segundo rasgo que podemos identificar en todas las imágenes del Word Press Photo of the Year, es una característica asociada a la fotografía de guerra como género: el hablar de una situación traumática aunque se hable de temas sociales. El trauma es una experiencia que amenaza física y emocionalmente el bienestar de una persona, y puede referirse a las personas tanto de forma individual como colectiva. A los procesos traumáticos les suele acompañar una pérdida de memoria, de datos que conforman la realidad y dejan detrás de sí el rastro de algo que no se ve, que se censura, de una presencia que no vemos, pero está ahí. Todas las fotografías de la serie, aluden a un horror que está más elidido que representado en la fotografía en sí misma. Cuando una mujer joven es abucheada y ridiculizada por acudir a una universidad de blancos, vemos ese hecho, pero también todo el horror de la esclavitud, el racismo y la explotación de una persona sobre otra, de un pueblo sobre otro. Vemos una imagen, y con ella el espectáculo de la representación, mientras intuimos que el horror es más profundo y más extendido en el tiempo de lo que la imagen muestra.

En tercer lugar, toda la serie de fotografías nos remite a un mundo de valores éticos. Es un ejemplo evidente de que ética y estética se muestran más unidas que nunca en estas imágenes que muestran ante todo el sufrimiento de la gente. Los horrores que padecen los seres humanos fotografiados, son causados por otros seres humanos, pero los espectadores estamos situados en una nueva categoría: de observadores de 
una tragedia, unidos por una sensibilidad común. La familia que llora la muerte de un niño, es cualquier familia; la niña que se agoniza atrapada en el lodo ante las cámaras, es cualquier niño que nos hace sentir que no lo podemos todo frente a la naturaleza. Este tipo de imágenes nos hablan de sobre todo de nuestra propia barbarie.

\section{2. "Nuestro sufrimiento" vs "el sufrimiento de "los/as otros/as"}

Como ya hemos comentado, la exhibición del dolor y la representación de la muerte en los medios de comunicación no ha parado de incrementar en las últimas décadas, hasta el punto de haberse convertido en una en "parte esencial de nuestras vidas" (Ilan, J. 2015: 229) como parte de lo visible en el espacio público. Esa exhibición del dolor, de la maldad y el sufrimiento están pautados y se mantienen de forma paradójica, dentro de los límites que enmarca las rutinas profesionales del fotoperiodismo. Por ejemplo, consideramos "obsceno" mostrar el sufrimiento de los que consideramos "nuestros", mientras nos consideramos con la libertad de mirar el sufrimiento de "los otros" (Sontag, S. 2003). Tal vez el ejemplo más ilustrativo es el hecho de que no hayamos visto prácticamente fotografías de la caída de las Torres Gemelas en el atentado del 11 de septiembre del 2001, en las que vimos sobre todo los edificios ardiendo, amasijos de hierros y cemento, pero pocas víctimas directamente afectadas por la masacre. Lo mismo ocurrió en los atentados de Madrid del 11 de marzo de 2004. En estos casos, la "fotogenia" de la catástrofe no justifica la exhibición de un sufrimiento que pueda hacerse insoportable. No ha habido desde la II Guerra Mundial ningún límite a la exhibición del sufrimiento humano a través de los medios, sobre todo si el sufrimiento es el de aquellos que no tienen que ver con nuestra realidad inmediata. La primera lección que parecen darnos los informativos de televisión es que "tenemos derecho a verlo todo". $\mathrm{Y}$ es un derecho sin límites cuando se trata de ver a aquellos colectivos o personas que no las consideramos como parte de un "nosotros". Los cuerpos y las almas destrozados en las guerras, los dramas vividos en las catástrofes naturales o la degradación a la que se condena a las personas que padecen el hambre y la miseria. En la fotogenia de este presente eterno, desaparecen los seres humanos de verdad, y nos quedan los signos que podemos consumir frente a una pantalla de televisión.

En línea con esa tendencia visual, muchos de los premios del Word Press Photo a lo largo de todos estos años muestran sin pudor el sufrimiento de aquellos a los que no se consideran parte de nuestra cultura, y por lo tanto, tenemos derecho a mirarlos y exhibirlos de forma natural y no problemática. Los niños y niñas que corren desnudos abrasados por el Napalm en Vietnam (1965); el niño muerto en la tragedia de Bhopal en la India (1985); o la niña atrapada en lodo después de la explosión de un volcán agonizando durante varios días en Colombia (1986), son ejemplos dramáticos de cuánto podemos y "queremos ver" del sufrimiento ajeno. Por otra parte, sabemos que los premios, hablan más de lo que una sociedad considera importante y valioso, que de aquellos individuos a los que se les conceden. En este caso, cumplen una función específica dentro de la profesión, ya que a través de ellos se realiza un debate sobre las rutinas, los límites o los estándares profesionales. Word Press Photo es el premio más prestigioso de su rango, capaz de elevar a categoría de "Arte" con mayúsculas las fotografías que premia, y a artistas a los fotógrafos que lo ganan. El arte parece unirse en este tipo de fotografias con la conciencia política que ha estado 
implícita en el trabajo fotoperiodístico. "Quiero mostrar las cosas que hay que cambiar", decía Hine en los años treinta... la cámara se convertía así en un testigo de la desigualdad social y la injusticia. Sus imágenes ganadoras nos proporcionan datos y reflejan los discursos profesionales, los contextos comunicativos y los límites de los estándares profesionales a nivel internacional (cit. En Liu, 2013: 457)

\subsection{Resultados del análisis con perspectiva de género}

El análisis cuantitativo sobre cuántas mujeres han ganado este premio es simple y reducido. Sólo cuatro fotoperiodistas mujeres lo han conseguido desde sus inicios: François Delmulder, 1976; Dayne Smith en 1999; Lara Jo Regan en el año 2000, y Jodi Bieber en el año 2010. El dato merece una explicación y una comparación analizando el papel de las mujeres en el fotoperiodismo, trabajo que no podemos emprender en este texto.

Respecto al análisis cualitativo, la primera cuestión sería preguntarnos si tiene siquiera sentido plantearnos una diferencia de género en las representaciones, ya que ¿no es la solidaridad un sentimiento extensivo a todo el género humano, que se caracteriza precisamente por poner en suspenso nuestros prejuicios de clase, de género o de raza? ¿Podemos decir que existe una tópica específica para representar el dolor de las mujeres? ¿Hay un dolor genuinamente femenino? Si bien las respuestas lógicas a estas preguntas, es que no hay en la vida humana diferencias respecto a la empatía o el dolor ajeno, es evidente que sí las hay a la hora de representar por qué sufren los hombres y las mujeres, o lo que es lo mismo, pensar a través de qué tipo de signos se representa este sufrimiento.

Ordenar el corpus de las 56 obras en claves de representación de género, nos ha supuesto algunas dificultades. Por ejemplo, podemos identificar el tema de una fotografía señalando quienes son los personajes principales de la representación, pero hay muchos casos en que las claves de ordenación que tomemos pueden ser discutibles. Hay pocas evidencias indiscutibles. Por ejemplo, podemos afirmar que predominan las fotos de grupos humanos sobre la representación de individuos solos. Sólo en seis casos se premiaron fotografías de varones solos, las correspondientes los años 1955, $1967,1969,1995$, frente a la de la única mujer que aparece totalmente en solitario del año 2011: una joven a la que su pareja había arrojado ácido a la cara.

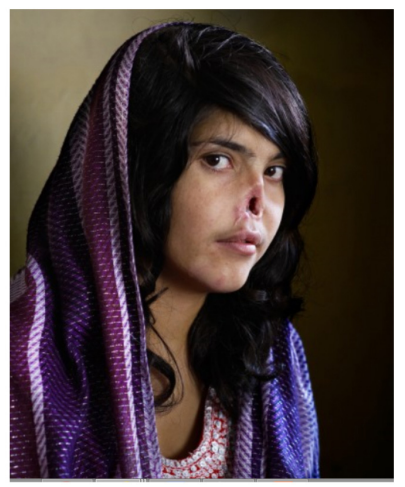

Imagen 1 
La fotografía fue tomada por Jodi Bieber, fotógrafa sudafricana, que hizo un retrato a Bibi Aisha, mujer de 18 años afgana, obligada a casarse por su familia y que fue desfigurada con ácido por su marido. Se trata de un retrato que podríamos calificar de convencional, en el que una mujer nos mira con dignidad y serenidad desde su desgracia. Sólo hay otra fotografía que podemos incluir en esta categoría de mujeres que miran a la cámara y se mantienen firmes frente al sufrimiento: la ganadora en 1957 presentada por Douglas Martin (Imagen 2). En esta obra, Dorothe Counts, una de las primeras estudiantes que acude a un centro de estudios racialmente mixto, es acosada por las burlas de sus compañeros blancos mientras camina erguida por la calle. Es una foto de grupo, en el que aparecen los jóvenes blancos utilizando la risa como arma de deslegitimación frente a los dos personajes negros que caminan serios hacia el final de los privilegios raciales. Ambas fotografías se salen de la forma más estereotipada de presentar a las mujeres: arrebatadas por las pasiones o el llanto por el sufrimiento y la muerte de los demás. Es evidente que el tropo recurrente es el de las mujeres llorando de forma desgarrada mientras son consoladas por otras mujeres. Por ejemplo en 1964 en la fotografía (Imagen 3) tomada por Don McCullin, una mujer chipriota llora la muerte de su marido durante el conflicto entre Grecia y Turquía. El lugar central de la imagen lo ocupa la cara de la mujer desencajada por el llanto, mientras su hijo la toca con su mano, no sabemos muy bien si para consolarla o para pedir consuelo. Varios niños miran la escena desde lejos. Mujeres y niños aparecen a menudo juntos en las imágenes. También en la fotografía premiada en 1999 tomada por Dayne Smith (Imagen 4) en el conflicto de Kosovo, una mujer es consolada por la muerte de su marido en este caso, el semblante no está descompuesto por el llanto, sino por el desvanecimiento, por pérdida de la consciencia de la realidad por el dolor sufrido, mientras manos masculinas y femeninas acuden a consolarla. Las mujeres desconsoladas, se convierten así en el tropo del llanto por la muerte irracional y generalizada tal y como podemos comprobar por la fotografía ganadora del certamen de 1998 tomada por Hocine (Imagen 5), en la que se retrata los desgarros de la guerra en Argelia.

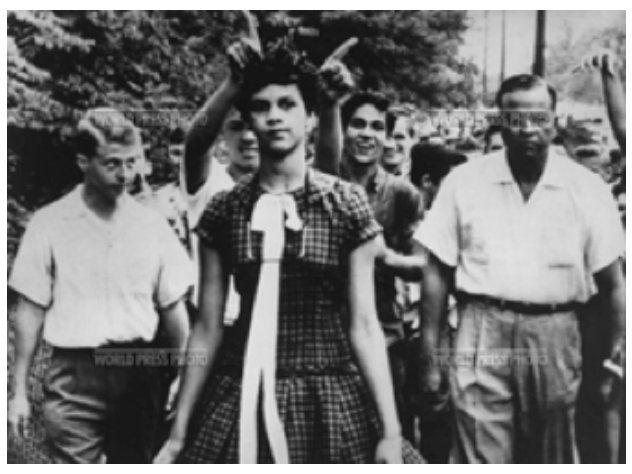

Imagen 2

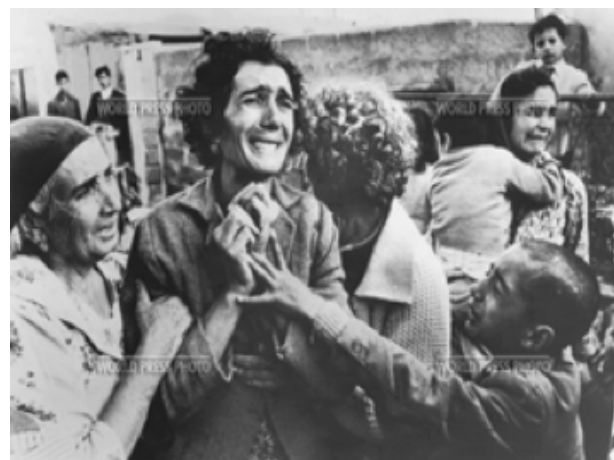

Imagen 3 


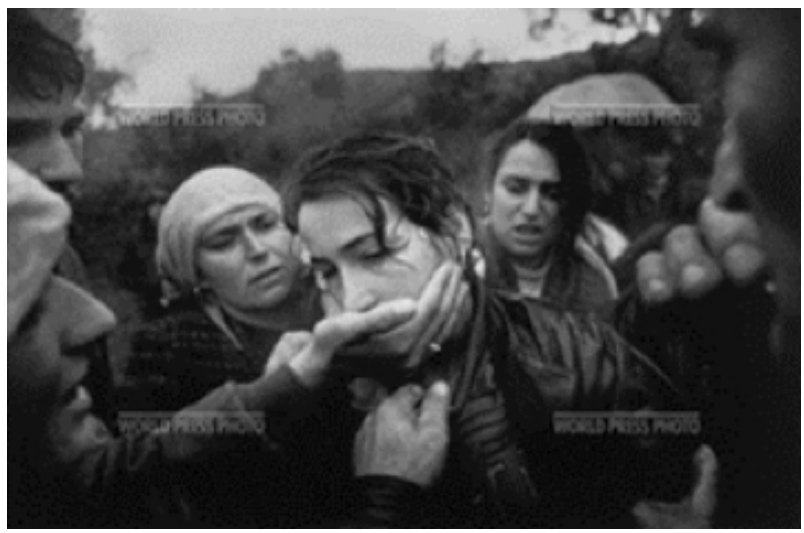

Imagen 4

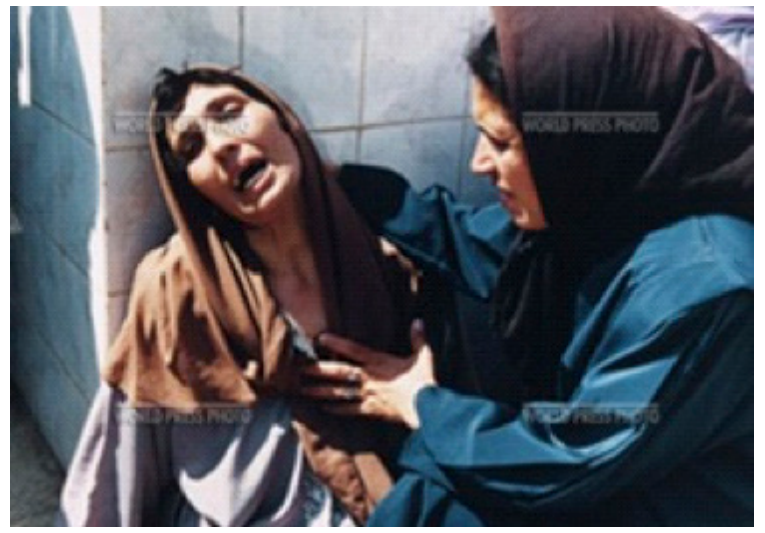

Imagen 5

En las fotografías de grupo como la instantánea de Françoise Demulder ganadora del premio en 1977 (Imagen 6), podemos ver un grupo de palestinos durante la guerra del Líbano. En ella varios personajes huyen del horror de la guerra, pero sólo una mujer palestina se detiene a rogar frente a un soldado, seguramente por el sufrimiento de los suyos y actuando como intermediara sentimental en su papel de representación de los padecimientos humanos. En una actitud muy similar aparece una mujer llorando ante la policía en la imagen premiada en 1988 (Imagen 7) y tomada por Anthony Suau en el sur de Corea. Más concretamente sabemos que la mujer llora desesperadamente por la detención de su hijo. Y sabemos que su llanto, como en la fotografía anterior, es totalmente inútil, porque no se dirige siquiera a aquellos que de verdad tienen el poder de cambiar la situación que ha producido su desesperación. Dentro de esta subcategoría de imágenes colectivas en las que sobresale una figura de una mujer descompuesta por el llanto podemos ver también la figura central del grupo familar que llora a su muerto una fotografía tomada por Georges Merillon en el Conflicto de Kosovo (Imagen 8) y que fue premiada en 1991. En esta imagen, no sólo es la mujer la que llora, sino todo el todo el grupo aparece representando el luto extremo. En este caso, vemos hasta qué puendo puede ser difícil catalogar este tipo de fotografías en una categoría o en otra. 
Las mujeres aparecen llorando la pérdida de los hijos y las personas queridas, sean causadas por la guerra o las catástrofes naturales. La fotografía (Imagen 9) ganadora del concurso en 1984 tomada por Mustafa Bozdemir nos descubre la realidad de una madre que encuentra que sus hijos han sido sepultados vivos en un terremoto en Turquía. Del mismo modo, en la fotografía de Arko Datta premiada en el año 2005 (Imagen 10), una mujer llora la muerte de los seres queridos ante una catástrofe natural: un tsunami en la India. Es significativa la capacidad de representar el dolor extremos en el cuerpo de las mujeres. En este caso, la cara prácticamente no se ve y es el cuerpo el que muestra un dolor extremo.

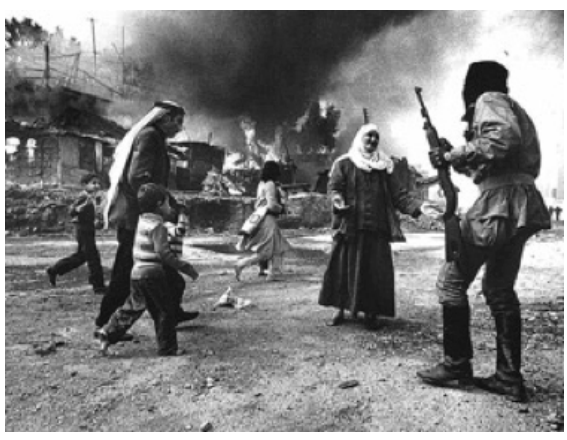

Imagen 6

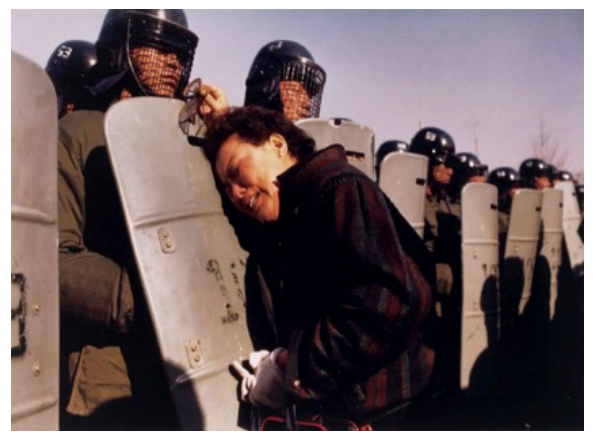

Imagen 7

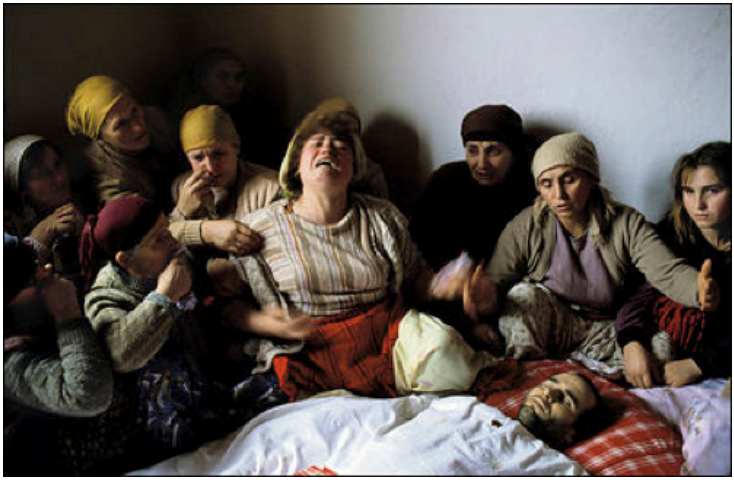

Imagen 8

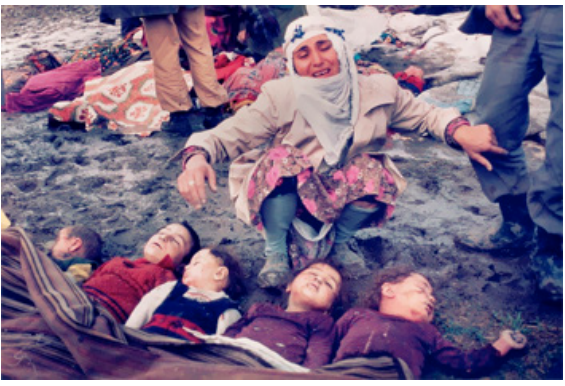

Imagen 9

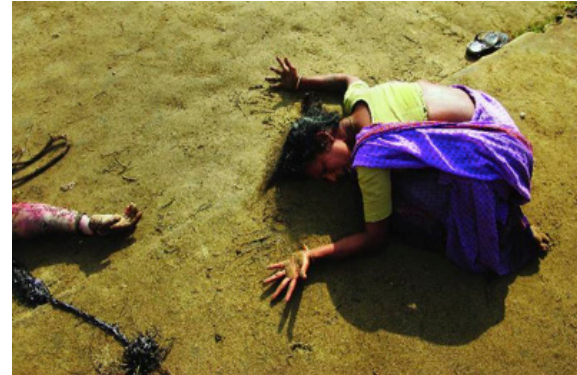

Imagen 10 
Estas últimas imágenes nos remiten a un tropo fundamental en la historia iconográfica femenina que es la representación de las mujeres como madres, es decir, en relación con el cuidado de los hijos. La madre, que se convierte en cuidadora en la vida y en la muerte, es uno de los grandes temas en la historia de la cultura occidental, consecuentemente la madre que acoge y consuela de las desgracias naturales o las catástrofes es uno de los tropos más recurrentes que podemos ver en estos premio. Mientras que las caras de los personajes suelen ser centrales en la representación, en algunos casos, pueden ser también elididas, y es el cuerpo el que toma el lugar central de la representación, aportando un valor dramático que alude a lo general frente a lo particular.

No sólo se despersonaliza el cuerpo de las madres, sino también el de los hijos y las hijas que aparecen fragmentados o cubiertos en las fotografias. Esta fragmentación del cuerpo de los hijos o de las hijas puede ser leída de dos maneras: por un lado sirve para subrayar aspectos dramáticos, tal y como veíamos en la imagen de Arko Datta (Imagen 10), y también en la ganadora de 1993, en la instantánea realizada por el fotógrafo de guerra James Nachtwey donde vemos como una madre levanta del suelo el cadáver de un bebé muerto de hambre en Somalia (Imagen 11) en el que el cuerpo aparece cubierto y despersonalizado. Pero, por otro lado, estas imágenes pueden ser utilizadas no para representar el dolor humano y universal sino los valores de calma y resignación asociados culturalmente a la condición femenina. Estas imágenes tienen un doble objetivo: se subraya la vulnerabilidad de la descendencia al mismo tiempo que se engrandece el papel de la madre -que casi siempre aparece o completa con una mayor entidad visualen su papel de cuidadora. Un ejemplo de ello es la fotografía de David Burnett (Imagen 12), donde se ve a una refugiada camboyana después de la caída de los Jemeres Rojos y cuyo carácter maternal sólo está denotado por unos pequeños pies de niño. En este caso, el cuerpo de la protagonista transmite la serenidad y la resignación de una cuidadora ante las circunstancias violentas que le rodeaban. Similar a la anterior es la foto de Finbarr O'Reilly (Imagen 13) en un campo de refugiados en Niger, donde una madre espera para obtener comida para su bebé y donde podemos ver el rostro de esta mujer y la mano de su hijo sobre sus labios. Estas imágenes parecen dramáticas pero calmadas y en ellas, si bien las madres personalizadas (Zazycka, M. 2012) y más o menos completas, en un ejercicio de sinécdoque visual, los hijos o hijas, aparecen fragmentados en alguno de sus miembros, sus manos o pies, simbolizando la parte por el todo: esos miembros no sólo nos hablan de la vulnerabilidad infantil en esa determinada circunstancia sino de la vulnerabilidad universal de la infancia.

Este tipo de representaciones maternales y sacrificales ha estado presente desde las primeras décadas del premio y han estado realizadas por fotógrafos de distintas culturas tal y como podemos ver, por ejemplo, en la fotografía de Kyōichi Sawada (Imagen 14) ganadora del certamen en 1965, donde se muestra la desesperación de una mujer por salvar a cuatro niños de las bombas americanas durante la Guerra del Vietnam. Esos mismos valores aparecen en la fotografía de Ovie Carter ganadora del certamen en 1974 (Imagen 15) en la que puso ante el mundo el problema del hambre en África y la India en un reportaje llamado The Faces of Hunger y donde retrataba los estragos de la sequía en la zona del Sahel (África) aludiendo a la capacidad protectora de las madres ante una catástrofe natural y repitiendo la fragmentación de la figura femenina que aparece condensada en dos manos cuidadoras. Este tipo de representaciones reproducen los elementos clásicos de la heroicidad femenina, que está cifrada sobre todo en la capacidad de resistencia y sacrificio. 
Este tipo de representación sacrifical de la mujer convertida en victimaria fue utilizada y revelada por los propios premios al elegir como ganadora en 2006 a una imagen equívoca del fotoperiodista Spencer Platt (Imagen 16) donde se veía a un grupo de jóvenes libaneses montados en un coche, tomando fotos después de un bombardeo en Líbano durante el conflicto Israel y Hezbollah. La foto, donde unas mujeres jóvenes y bellas son las protagonistas, levantó polémica por estar asociada a valores como riqueza, despreocupación y voyeurismo ante la tragedia, sin embargo, las personas retratadas eran víctimas. Víctimas que buscaban a sus parientes, quizás enterrados debajo de los escombros, tal y como revelaron en una entrevista a la BBC. Sus imágenes, sin embargo, no correspondía a la de la mujer-víctima que los propios World Press Photo habían estado fomentando a lo largo de su historia.

Por último deberíamos citar a la obra ganadora del español Samuel Aranda (Imagen 17) en el año 2012 en la que una mujer velada abraza a un hombre herido en un contexto sanitario durante el conflicto del Yemen y que resume muy bien aspectos que básicos que hemos visto en otras imágenes ganadoras como recurrrir a modelos clásicos de la iconografía a la hora de realizar de las imágenes (en este caso la pasión de Cristo y la Virgen de los Dolores), la fragmentación u ocultación de los rasgos particulares de los protagonistas (el rostro tanto de la mujer como la del hombre aparecen ocultos), la utilización del cuerpo para expresar dolor y la reducción a estereotipos.

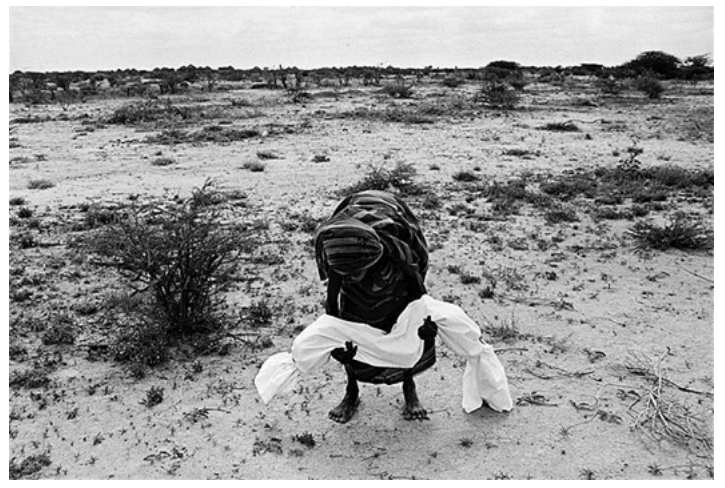

Imagen 11

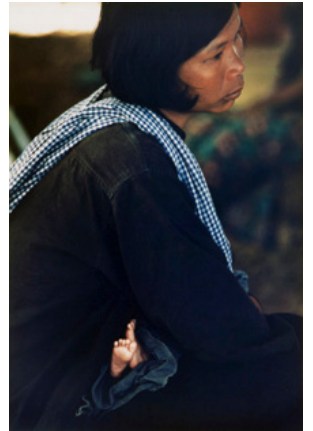

Imagen 12

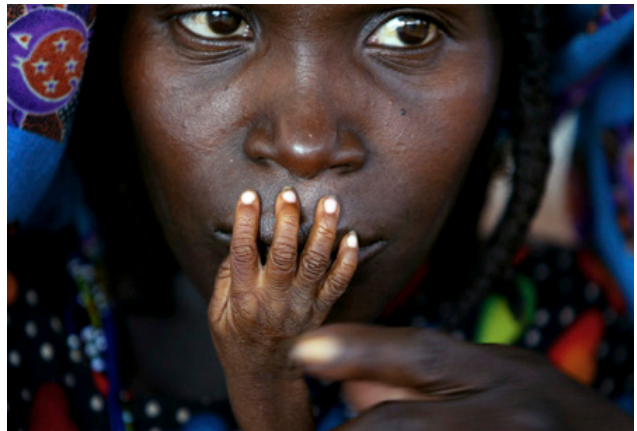

Imagen 13 


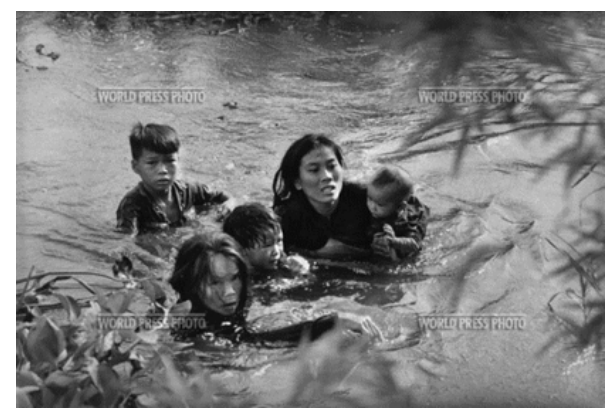

Imagen 14

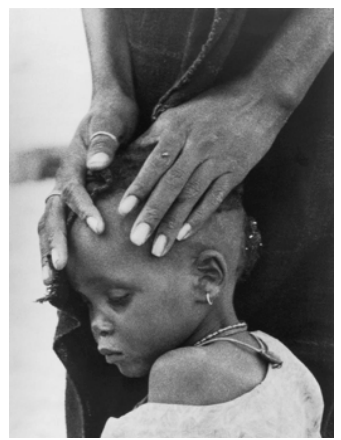

Imagen 15

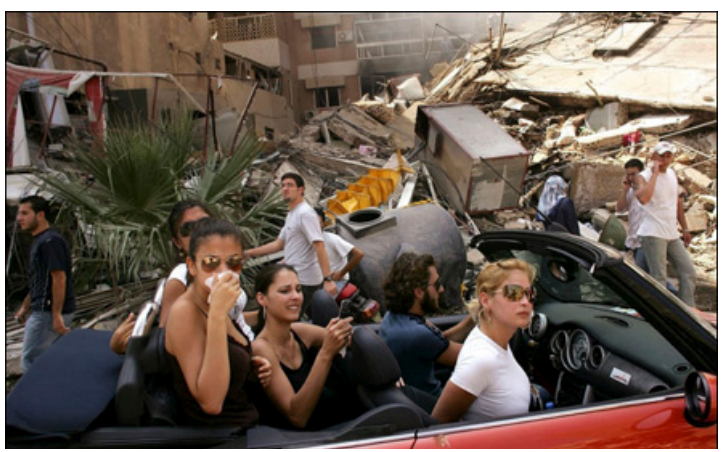

Imagen 16

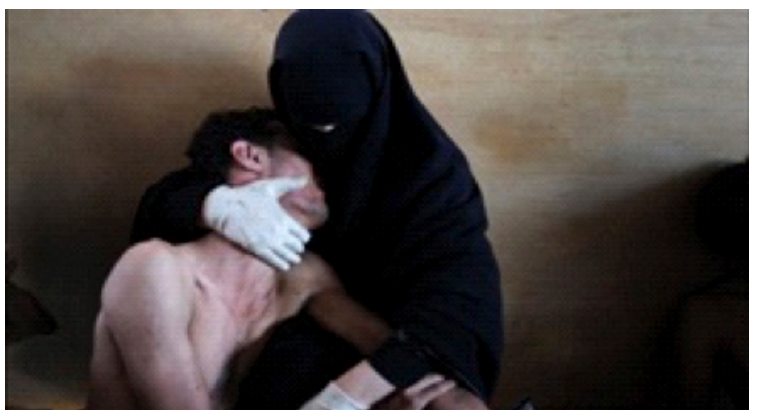

Imagen 17

\section{Conclusiones}

1.- En las fotografías ganadoras de la serie, los hombres son más a menudo los personajes principales de la escena que se representa por encima de las mujeres. Los papeles que encarnan en ellas son además más variados: luchan, matan, se defienden, sufren accidentes, a veces se desmoronan, pero en todo caso son agentes activos de la realidad social. Los roles masculinos, son igual de estereotipados pero, como en la vida real, a los hombres adultos se les representa desempeñando una mayor cantidad y variedad de papeles sociales: son los accidentados, pero también los deportistas, 
los que observan, pero también los que actúan, son victimarios y víctimas, los que agreden, pero también los que ayudan, los que roban bancos, los que asesinan, los que descansan de una situación de estrés, los que se inmolan, los que lloran, los que sufren los golpes de estado, los genocidas, los enfermos o los que se enfrentan al poder de forma violenta.

2.- Las mujeres aparecen sobre todo como portadoras del sufrimiento por los demás. Son más a menudo las cuidadoras, las que lloran a los muertos. Junto con los niños, son representadas siempre como víctimas. Su sufrimiento es el mal que afecta a los otros. Las mujeres son las que lloran, las que sobreviven, las que cuidan y acarician a los niños. Las mujeres protegen, ruegan ante los soldados por la vida de los suyos. No hay en ningún caso intereses o ideales políticos en juego (salvo en la de 1957 sobre el fin de la segregación racial). No es problemático que las mujeres encarnen el papel de cuidadoras, pero sí lo es la reducción de representaciones de otro tipo, ya que reduce las "posibilidades de ser" en el mundo real.

3.- El tropo más representado es el de las mujeres llorando a los muertos, heridos o desaparecidos. En los últimos años del premio, los galardones ha recaído en obras que no aluden directamente a problemas de tipo político, y se han ido desplazando a hacia el terreno de la solidaridad. Las mujeres y los niños, aparecen en este contexto como las víctimas de un mundo injusto: mujeres inmigrantes con sus niños, las mujeres mutiladas, las víctimas la violencia de género.

4.- La infancia está también fuertemente estereotipada: los niños aparecen siempre como las víctimas de la barbarie adulta, de los accidentes o los desastres naturales... cuando toman las armas son el epítome de la deshumanización y la barbarie provocada por los adultos.

5.- Los procesos visuales que permiten este proceso de estereotipación son, tal y como hemos visto tres: recurrir a esquemas visuales presentes en la cultura Occidental, fragmentar las figuras o eliminar y ocultar el rostro de los y las protagonistas. Este mecanismo establece una interesante tensión dentro de estas obras ya que, debido a su carácter realista e inmediato, pretenden ser informativas y, por lo tanto, históricas y reveladoras de hechos concretos pero, al mismo tiempo, las fotografías premiadas, por ajustarse convencionalmente a ciertos esquemas iconográficos imperecederos nos hablan de elementos a-históricos como el sufrimiento humano universal o la maternidad. Al realizar esta operación despolitizan precisamente los hechos históricos que pretenden retratar fielmente.

6.- El carácter conservador de las obras seleccionadas se traslada a los esquemas de género que representan: una profunda "otredad" en el sufrimiento femenino. En las imágenes de los hombres, hay un aquí y ahora de la guerra o los accidentes. En las representaciones femeninas, las historias de sufrimiento son historias de relación con otros sufrientes. Cuando observamos a las mujeres llorando, sabemos que su dolor es un dolor por los demás: un familiar muerto, por unos hijos desaparecidos o en peligro.

7.- En el fotoperiodismo se construyen y reconstruyen el universo dicotómico que dibuja lo femenino como sufriente, frente a los medios eufóricos publicitarios que han introducido la teoría postfeminista del genderblend, haciendo como si ya de una vez por todas se estuviesen diluyendo las fronteras entre lo femenino y la masculino. En las fotografías que hemos analizado no ocurre esto: las mujeres, sobre todo lloran por los demás, cuidan y acogen. Su sufrimiento no es un sufrimiento esencial y ensimismado en ellas mismas. Es un sufrimiento por el otro, por los otros. 
Es un sufrimiento sin la esencia de la individualidad que se le exige a la identidad posmoderna.

\section{Bibliografía citada}

Aiello, Giorgia \& Woodhouse Anna (2016) "When corporations come to define the visual políticas of gender”, Journal of Language and Politicas 15: 3. Págs. 352- 368.

Arend, H. (1967) Sobre la revolución. Madrid, Revista de Occidente.

Barthes, R. (1997) La aventura semiológica, Barcelona, Paidos.

Beck, U. (2000) What is Globalization? Cambridge, Polity Press.

Bock, A. Isermann, H. y Knieper, T. (2011), "Quantitative content analysis of the visual. En Margolis, E. y Pauwels, L. (Eds.) The SAGE Handbook of Visual Research Methods, London, Sage.

Boltanski, L. (1999) Distant Suffering: Morality, Media and Politics. Cambridge: Cambridge University Press.

Buell, H. (1999) Moments: The Pulizer Prize-Winning Photographs-A Visual Chricle of Our Time, New York: Black Dog and Leventhal.

Butler, J. (2006) Precarious Life: The Powers of Mourning and Violence, London, Verso.

Butler, J. (2009) Frames of War: When is Life Grievable? London, Verso.

Choularaki, L. (2010), "Post-humanitarianism: humanitarian communication beyond a politics of pity, International Journal of Cultural Studies 13 (2): págs. 107- 127.

Cottle, S. (2009) “Journalism an globalization”. En K. Wahl-Jogensen \& T. Hanitzsch (Eds.), The handbook of journalism studies, Ne w York: Routledge. Págs. 341- 356.

Didi-Huberman, D. (2008) Images in Spite of All, Chicago: University or Chicago Press.

Fassin, D. (2015). "La economía moral del asilo. Reflexiones críticas sobre la "crisis de los refugiados" de 2015 en Europa", Revista de Dialectología y Tradiciones Populares. Vol. LXX, No 2, págs. 277- 299.

Foucault, M. (1999) La arqueología del saber, Madrid, Siglo XXI, 1999.

Fraser, N. (1997). Iustitia interrupta. Reflexiones críticas sobre la posición postcolonialista, Bogotá, Siglo del Hombre Editores.

Geertz, C. (1997). La interpretación de las culturas. Barcelona, Gedisa.

Ghattas, K (2007), "Lebanon war image causes controversy", BBC News, http://news.bbc. co.uk/2/hi/middle_east/6385969.stm

Greenwood, K., \& Smith, C. Z. (2009). “Conventionalization in feature photography: A study of winning photographs in the Pictures of the Year International competition". Journalism Practice, 3, 140- 161.

Hall, S. (1997) Representation: Cultural Representations and Signifying Practices, London, Sage.

Hardt, H. (Eds.) Picturing the past: Media, history and photography, Champaign, IL: University of Ilinois Press. Págs. 159-181.

Höoijer, B. (2004) "The discourse of global compassion: the audience and media reporting of human suffering" en Media, Culture \& Society, Vol. 26(4): 513-531

Ilan, Jonathan (2015). "Over a dead body: International coverage of grief”, Semiotica, No 2015: 292-242.

Kedra, Joanna (2013) “To See More: A Model for Press Photograph Story Analysis”, Journal of Visual Literacy, Vol. 32. $\mathrm{N}^{\mathrm{o}} 1,27-50$. 
Kim, H. S. y Smith Z. C. (2005). "Sixty years of showing the world to America: Pulitzer Prize-winning photographs", 1942-2002. International Communication Gazette 67(4) 307-323.

Lewis, S. C., Kaufhold, K, y Lasorsa, D. L. (2010), “Thinking about citizen journalism: The philosophical and practica challenges of user-generated content for community newspapers, Journalism Practice, 4, págs. 163-170.

Liu, J. (2013), "Professional discourse in winning images: objectivity and profesional boundaries in environmental news images in the World Press Photo contest, 1992- 2011", Chinese Journal of Communication, Vol. 6. №. 4, págs.. 456- 481.

Machin, D. (2004), "Building the world's visual language: the increasing global importance of image banks in corporate media, Visual Communication 3 (3), págs. 316-336.

Mäenpää, Jenni (2014). "Rethinking Photojournalism. The Changing Work Practices an Professionalism of Photojournalism in the Digital Age", Nordicom Review, 35 (2014) 2, pp. 91-104.

Mielczarek, Natalia (2013) The 2011 World Press Photo: A study of a modern-day Hagar in Yemen through the prism of collective memory in Islam, Journal of Arab\&Muslim Media Research, Vol. 6. No 2\&3: 217- 232

Moeller, S. D. (1999) Compassion Fatigue: How the Media Sell Disease, Famine, War and Death, New York, Routledge.

Newton, J. H. (2008) The Burden of Visual Truth: The Role of Photojournalism in Mediating Reality, Mahwah, New York.

Rodgers, S.; Kenix, L. J; Thorson, E. (2007) "Stereotypical Portrayals of Emotionality in News Photos", Mass Communication \& Society, 10 (1), págs.. 119- 138.

Rose, G. (2012). Visual methodologies: An introduction to researching whith visual materials, London, Sage.

Rosler, Marta (2004). "Dentro, alrededor y otras reflexiones. Sobre la fotografía documental”, en Ribalta, Jorge (ed.) Efecto real. Debates posmodernos sobre fotografia, Barcelona, Gustavo Gili.

Schwartz, D. (1999). “Objective representation: Photographs as facts”. En B. Brenen \&

Sontang, S. (2003). Regarding the Pain of Others. New York, Farrar, Straus and Giroux.

Wright, T (2000). Refugees on Screen. Working Paper. Refugee Studies Center. University of Oxford. https://www.rsc.ox.ac.uk/publications/refugees-on-screen

Zarzycka, M (2012) "Madonnas of warfare, angels of poverty, Photographies 5(1), págs. 71-85.

Zarzycka, M. y Kleppe, M. (2013) "Awards, archives, and affects: tropes in the Word Press Photo contest 2009-11”, Media, Cultura y Sociedad, 35 (8) 977-995. 